\title{
Macrophages are a significant source of type 1 cytokines during mycobacterial infection
}

\author{
Jun Wang, ${ }^{1}$ Julia Wakeham, ${ }^{1}$ Robin Harkness, ${ }^{2}$ and Zhou Xing ${ }^{1}$ \\ ${ }^{1}$ Department of Pathology and Molecular Medicine, and Division of Infectious Diseases, Centre for Gene Therapeutics, \\ McMaster University, Hamilton, Ontario, Canada L8N $3 Z 5$ \\ ${ }^{2}$ Pasteur Mérieux Connaught, North York, Ontario, Canada M2R 3T4 \\ Address correspondence to: Zhou Xing, Health Sciences Centre, Room 4H19, Department of Pathology and Molecular Medicine, \\ McMaster University, Hamilton, Ontario, Canada L8N 3Z5. Phone: (905) 525-9140, ext. 22471; Fax: (905) 522-6750; \\ E-mail: xingz@fhs.csu.mcmaster.ca
}

Received for publication January 7, 1999, and accepted in revised form February 19, 1999.

T-helper 1 (Th1) cells are believed to be the major producer of the type 1 cytokine interferon- $\gamma($ IFN- $\gamma)$ in cellmediated immunity against intracellular infection. We have investigated the ability of macrophages to release type 1 cytokines and their regulatory mechanisms using both in vivo and in vitro models of pulmonary mycobacterial infection. During pulmonary infection by live Mycobacterium bovis bacilli Calmette-Guérin (BCG) in wild-type mice, lung macrophages released interleukin-12 (IL-12), IFN- $\gamma$, and tumor necrosis factor- $\alpha$ (TNF- $\alpha$ ), and expressed surface activation markers. However, macrophages in infected IL-12-/- mice released TNF- $\alpha$ but not IFN- $\gamma$ and lacked surface activation makers. In freshly isolated lung macrophages from naive IL-2- ${ }^{-/}$mice, mycobacteria alone released TNF- $\alpha$ but not IFN- $\gamma$, whereas exogenously added IL12 alone released a minimum of IFN- $\gamma$. However, these macrophages released large quantities of IFN- $\gamma$ upon stimulation with both mycobacteria and IL-12. In contrast, mycobacteria and exogenous IFN- $\gamma$ released only a minimum of endogenous IFN- $\gamma$. Endogenous IL-18 (IFN- $\gamma$-inducing factor) played little role in IFN- $\gamma$ responses by macrophages stimulated by mycobacteria and IL-12. Our data reveal that macrophages are a significant source of type 1 cytokines during mycobacterial infection and that both IL-12 and intracellular pathogens are required for the release of IFN- $\gamma$ but not TNF- $\alpha$. These findings suggest that macrophages regulate cell-mediated immunity by releasing not only IL-12 and TNF- $\alpha$ but also IFN- $\gamma$ and that full activation of IFN- $\gamma$ response in macrophages is tightly regulated.

J. Clin. Invest. 103:1023-1029 (1999).

\section{Introduction}

Development of acquired T-helper 1 (Th1) cellular immunity is essential to the eradication of intracellular pathogens such as mycobacteria. This protective immunity is characterized by a polarized production of type 1 cytokines including interleukin-12 (IL-12), interferon- $\gamma$ (IFN- $\gamma$ ), and tumor necrosis factor- $\alpha(\mathrm{TNF}-\alpha)$, and by tissue macrophage granulomatous inflammation $(1,2)$. It is believed that during intracellular infections, IL-12 is released from macrophages and operates as a link between innate and acquired immunities by inducing Th1 phenotype differentiation and stimulating $\mathrm{T}$ and natural killer (NK) cells to release IFN- $\gamma(3,4)$. In addition to its role in T-cell activation, IFN- $\gamma$ is known to be central to the full-blown activation of macrophages, the ultimate effector cells in controlling intracellular infection. In comparison, TNF- $\alpha$ may be released not only from $T$ cells but also from macrophages, participating in a number of antimicrobial immune and inflammatory events $(5,6)$. Recent experimental and human observations by ourselves and others have lent strong support to the important role of each of these type 1 cytokines in host resistance to intracellular infection, particularly mycobacterial infection (7-13).

While $\mathrm{T}$ cells are critical for adequate macrophage activation through their production of IFN- $\gamma$, it remains unclear whether macrophages also play a direct, vigorous role in their own activation in host defense against intracellular infection. A wealth of literature has demonstrated that macrophages are able to release large quantities of a wide array of cytokines, including IL-12 and TNF- $\alpha$, in response to such common stimuli as lipopolysaccharide (LPS) in vitro $(3,4,6)$. Under these conventional culture and stimulatory conditions, however, macrophages do not release IFN- $\gamma$ in a significant manner (14-16). Indeed, the difficulty in inducing this cytokine from macrophages has further been noted in two recent studies in which macrophages failed to release IFN- $\gamma$ unless they were primed in vitro for an extended period of time with repeated dosing of IL-12 (17) or costimulated by high doses of IL-12 and IL-18 (18). Thus, whether macrophages release this important type 1 cytokine, and which factors are required for an optimal IFN- $\gamma$ response in macrophages during intracellular bacterial infection both in vivo and in vitro, have remained unknown.

In this study, we have sought to address these important issues by using in vivo and in vitro models of pulmonary mycobacterial infection in wild-type control and IL-12 p40 gene-deficient (IL-12-/-) mice and investigated (a) whether macrophages release IL-12, IFN- $\gamma$ and TNF- $\alpha$; $(b)$ if so, whether IL-12 is involved in IFN- $\gamma$ and TNF- $\alpha$ responses; $(c)$ whether IL-12 or microbial agents, or both, are directly required for IFN- $\gamma$ release by macrophages; and (4) what the role of other cytokines in such IFN- $\gamma$ responses is. 
a

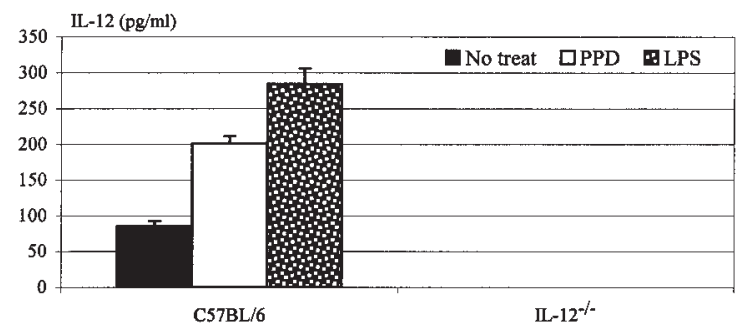

b

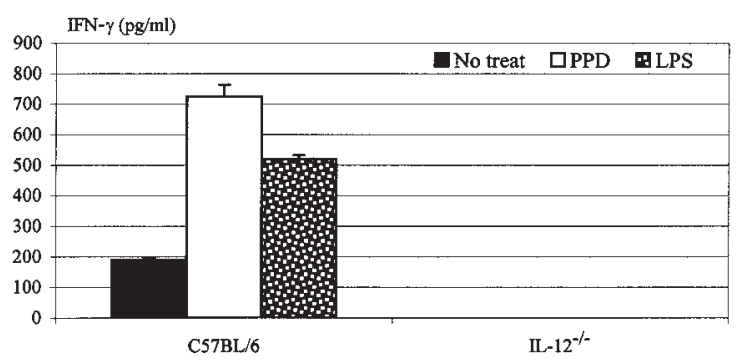

c

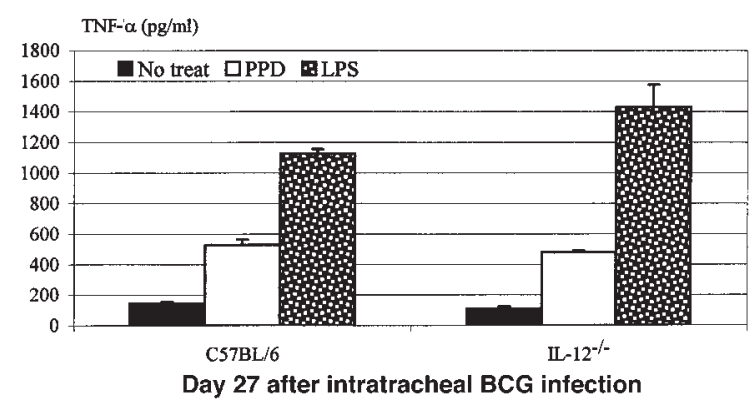

Figure 1

Type 1 cytokine production from pulmonary macrophages during mycobacterial infection. Macrophages were isolated from the lungs of C57BL/ 6 and IL-12-/- mice 27 days after infection and cultured with or without PPD or LPS stimulation at $37^{\circ} \mathrm{C}$ for $72 \mathrm{~h}$. The supernatants were measured for $(\boldsymbol{a}) \mathrm{IL}-12,(\boldsymbol{b}) \mathrm{IFN}-\gamma$, and $(\boldsymbol{c})$ TNF- $\alpha$ by specific ELISA kits. The results are expressed as means \pm SEM from triplicate samples for each condition and are representative of three independent experiments. IL-12, interleukin-12; IFN- $\gamma$, interferon- $\gamma$; TNF- $\alpha$, tumor necrosis factor- $\alpha$; PPD, M. tuberculosis-derived purified protein derivative; LPS, lipopolysaccharide.

\section{Methods}

Mice. The generation and characterization of IL-12/- mice have been described elsewhere (19). Both male and female IL-12-/mice with a C57BL/ 6 background (the breeding pair was kindly provided by J. Magram, Hoffmann La Roche Inc., Nutley, New Jersey, USA) were bred and maintained in the Level B pathogen-free facility at McMaster University Animal Quarter. Mice were used at the age of 8-14 weeks. C57BL/6 mice at the same age were used as wild-type controls (Harlan Bioproducts for Science, Indianapolis, Indiana, USA).

Reagents. An attenuated live strain of Mycobacterium bovis bacille Calmette-Guérin (BCG) and the mycobacterial antigen PPD ( $M$. tuberculosis-derived purified protein derivative) were obtained from Connaught Laboratories Ltd. (North York, Ontario, Canada). Dead BCG was prepared by boiling live BCG for $10 \mathrm{~min}$. RPMI-1640 medium was supplemented with $10 \%$ FCS, 100 U/ml penicillin, $100 \mu \mathrm{g} / \mathrm{ml}$ streptomycin and $2 \mathrm{mM}$ of L-glutamine. Lipopolysaccharide (LPS) (055:B5 E. coli-derived) was purchased from Sigma Chemical Co. (St. Louis, Missouri, USA). Phycoerythrin-labeled anti-mouse Mac1 and biotinylated anti-mouse MHC class II M5 antibodies were purchased from PharMingen
(Mississauga, Ontario, Canada). IL-12- or IFN- $\gamma$-containing supernatants were generated by transducing A549 cells with a replication-deficient adenoviral gene-transfer vector expressing murine IL-12 or IFN- $\gamma(20)$. The concentration of murine IL-12 or IFN- $\gamma$ in these supernatants was calibrated by ELISA. A control virus (Addl70-3) without transgene was used to generate control supernatants, which were shown not to have any measurable effects (data not shown). An anti-mouse IL-18 monoclonal antibody was purchased from R\&D Systems Inc. (Minneapolis, Minnesota, USA). The neutralization dose ${ }_{50}\left(\mathrm{ND}_{50}\right)$ for this antibody was $4-10 \mu \mathrm{g} / \mathrm{ml}$ of the antibody for $10 \mathrm{ng} / \mathrm{ml}$ of murine IL-18.

In vivo model of pulmonary mycobacterial infection. Live BCG were used to establish an in vivo model of pulmonary mycobacterial infection as described previously (7). Briefly, BCG stock solution was diluted in PBS and sonicated to ensure proper dispersion of mycobacteria. Mice were infected by intratracheal instillation of live BCG at a dose of $0.5 \times 10^{6} \mathrm{CFU}$ in a total volume of $40 \mu \mathrm{l}$ per mouse following a procedure described previously $(7,21)$.

Purification and ex vivo culture of total lung tissue macrophages from mice infected with mycobacteria. C57BL/6 and IL-12-/- mice were sacrificed at days 27 and 43 after infection. The lungs were removed from the chest with the heart and a portion of the trachea intact. Pulmonary vasculature was perfused with $5 \mathrm{ml}$ of warm $\left(37^{\circ} \mathrm{C}\right)$ calcium- and magnesium-free $1 \times$ HBSS containing $5 \% \mathrm{FBS}, 100 \mathrm{U} / \mathrm{ml}$ penicillin, and $100 \mu \mathrm{g} / \mathrm{ml}$ streptomycin via the right ventricle of the heart. Total mononuclear cells were isolated from the lungs by collagenase digestion and discontinuing gradient centrifugation as described previously (7). This mononuclear cell preparation contained $60-70 \%$ macrophages and $20-30 \%$ lymphocytes, with less than $10 \%$ of cells being neutrophils and epithelial cells. Cells were resuspended in RPMI1640 medium and seeded into 24-well plates at a density of $10^{6}$ cells per well. After $2 \mathrm{~h}$ of incubation at $37^{\circ} \mathrm{C}$, macrophages were enriched by removing nonadherent cells by three rigorous washes with warm PBS. Adherent macrophages were cultured in 0.5 $\mathrm{ml}$ of RPMI- 1640 medium with or without $8 \mu \mathrm{g} / \mathrm{ml}$ of PPD or $1.6 \mu \mathrm{g} / \mathrm{ml}$ of LPS for $72 \mathrm{~h}$ at $37^{\circ} \mathrm{C}$. The supernatants were collected and stored at $-20^{\circ} \mathrm{C}$ until cytokine measurement.

Isolation and in vitro culture of lung macrophages from naive IL-12-1mice. A bronchoalveolar lavage procedure was carried out to isolate lung macrophages from naive noninfected IL-12-/- mice as described previously (7). The mouse lung was lavaged with a total of $2.6 \mathrm{ml}$ of PBS in six aliquots $(0.3 \mathrm{ml} \times 2$ and $0.5 \mathrm{ml} \times 4)$ through a polyethylene tube (Becton Dickinson Microbiology Systems, Sparks, Maryland, USA) cannulated into the mouse trachea. Approximately $0.6-1 \times 10^{6}$ cells per mouse were consistently obtained and more than $98 \%$ of these cells were macrophages. These cells were resuspended in RPMI-1640 culture medium and cultured in 96-well plates at a density of $0.1 \times 10^{6}$ cells/well with or without various stimuli, including $50 \mathrm{CFU} /$ cell of live BCG or heat-inactivated BCG, $1.6 \mu \mathrm{g} / \mathrm{ml}$ of LPS, $8 \mu \mathrm{g} / \mathrm{ml}$ of PPD, 400 $\mu \mathrm{g} / \mathrm{ml}$ ovalbumin (OVA), or a combination of BCG or LPS plus IL-12- or IFN- $\gamma$-containing supernatants in a total volume of 0.25 $\mathrm{ml}$ for $72 \mathrm{~h}$ at $37^{\circ} \mathrm{C}$. In some experiments, macrophages were cultured in the presence of an IL-18 neutralizing antibody, in addition to the above stimuli. The supernatants were collected and stored at $-20^{\circ} \mathrm{C}$ until cytokine measurement.

Cytokine measurements. The level of cytokines in culture supernatants was determined by using mouse-specific ELISA kits. IL12 ELISA kits were purchased from BioSource International (Camarillo, California, USA.) IFN- $\gamma$ and TNF- $\alpha$ ELISA kits were purchased from R\&D Systems Inc. The sensitivity of detection for all of these ELISA kits was less than $5 \mathrm{pg} / \mathrm{ml}$.

Evaluation of macrophage activation by immunostaining and FACS analysis. Both C57BL/6 and IL-12/- mice were infected with BCG for 27 days. Total lung mononuclear cells were isolated by an enzymatic dispersion protocol as described above. Approximately $5 \times 10^{5}$ cells were incubated with anti-FcR antibody $2.4 \mathrm{G} 2$ on ice 
for $15 \mathrm{~min}$ and then labeled with anti-MHC class II biotinylated M5 antibody on ice for $30 \mathrm{~min}$. After wash with PBS/0.2\% BSA, the cells were labeled with phycoerythrin-conjugated anti-mouse Mac 1 antibody for $30 \mathrm{~min}$ on ice. Data were collected by FACScan (Becton Dickinson Immunocytometry Systems, San Jose, California, USA). Analysis was performed by gating on the macrophage-rich area excluding lymphocytes and dead cells.

\section{Results}

Requirement of IL-12 for release of IFN- $\gamma$, but not TNF- $\alpha$, by macrophages during pulmonary mycobacterial infection. We have recently demonstrated in a model of pulmonary BCG mycobacterial infection in wild-type and IL-12-/mice that IL-12 is imperative for the release of type 1 cytokines IFN- $\gamma$ and TNF- $\alpha$ in the lung $(7,8)$. In the absence of IL-12, T cells from the lung failed to release IFN- $\gamma$ in response to mycobacterial antigen recall challenge in vitro (7). As a result of such lack of type 1 cytokine responses, there was an impaired tissue granulomatous response in the lung and a continuing increase in the number of bacilli both in the lung and spleen over a period of 71 days, in contrast to an effective control of infection in their immunocompetent counterparts $(7,8)$. The

a

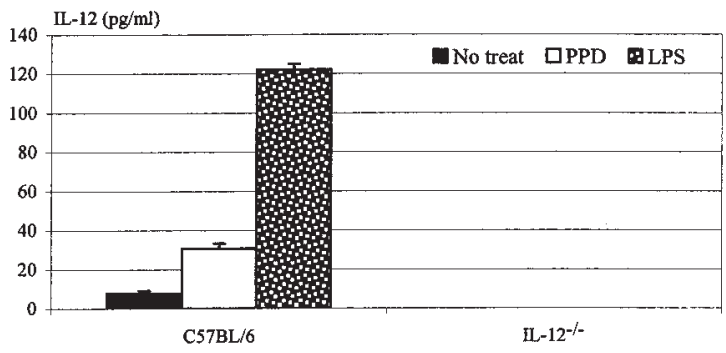

$\boldsymbol{b}$

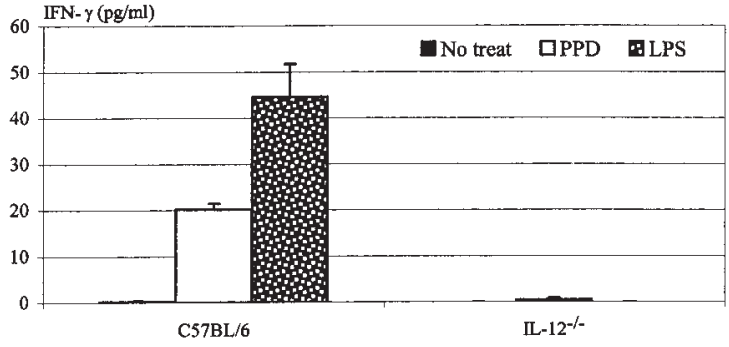

C

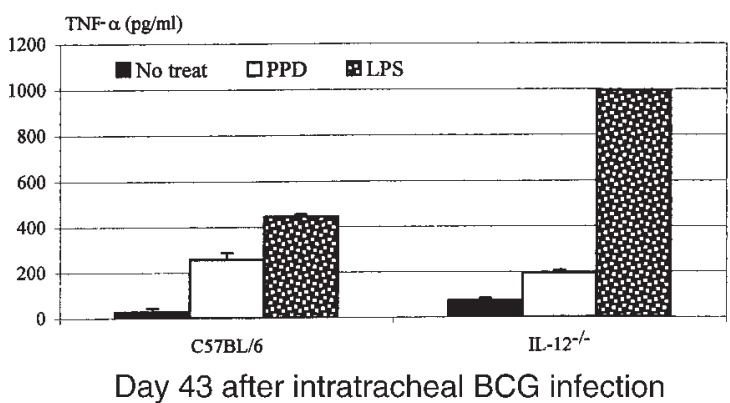

Figure 2

Type 1 cytokine production from pulmonary macrophages isolated 43 days after mycobacterial infection. Culture conditions were identical to those in Figure 1. role of IL-12, however, in macrophage activation and cytokine responses during pulmonary mycobacterial infection remains to be determined. To this end, we set out to compare the capability of macrophages to release type 1 cytokines in wild-type and IL-12/- mice after intratracheal inoculation of live M. bovis BCG . Lung macrophages isolated at days 27 and 43 after infection were cultured with or without PPD or LPS stimulation. Notably, macrophages obtained at day 27 from wild-type mice spontaneously released significant amounts of IL-12, IFN$\gamma$, and TNF- $\alpha$ (Figure 1, $a-c$ ), suggesting the activation of these macrophages and their contribution to type 1 cytokine production in the lung. The levels of these cytokines increased further upon stimulation with PPD or LPS (Figure 1). In sharp contrast, there was no spontaneous release of IFN- $\gamma$ by lung macrophages isolated from the lungs of IL-12-/- mice at day 27 after infection, and these cells also failed to release any IFN- $\gamma$ upon stimulation (Figure 1b). These results suggest the involvement of IL-12, directly or indirectly, in IFN- $\gamma$ responses by macrophages in the lung. Unlike IFN- $\gamma$, similar amounts of TNF- $\alpha$ were spontaneously released from macrophages from IL-12-/- and wild-type mice, and both responded similarly to PPD or LPS stimulation in releasing TNF- $\alpha$ (Figure 1c). This suggests that TNF- $\alpha$ response by macrophages during pulmonary mycobacterial infection is not dependent on IL-12. Similarly, by day 43 after infection, while the level of spontaneous release of IL-12, IFN$\gamma$, and TNF- $\alpha$ by macrophages from wild-type mice was decreased, these macrophages were still able to release all of these cytokines upon stimulation with PPD or LPS (Figure 2, $a-c$ ). In keeping with the observations at day 27, while upon stimulation macrophages from IL-12/- mice still released no IFN- $\gamma$, they released TNF- $\alpha$ at a level comparable to that by cells from wild-type mice (Figure 2, $a-c$ ).

Requirement of IL-12 for macrophage phenotypic activation during pulmonary mycobacterial infection. Having demonstrated a lack of IFN- $\gamma$ responses by macrophages from infected IL-12/- mouse lung, we examined whether there was a lack of phenotypic activation of these cells. To this end, total lung mononuclear cells were isolated from wildtype and IL-12-/- mice 27 days after infection, labeled with monoclonal antibodies to MHC class II (macrophage activation marker) or Mac 1 (macrophage phenotype/activation marker) and analyzed by FACS analysis by gating on the macrophage-rich population (Figure 3, $a$ and $b$ ). We found that there was a much greater percentage of macrophages from wild-type mice than from IL- $12^{-/-}$mice that expressed bright MHC class II (46\% vs. $20 \%$ ) or Mac 1 (73\% vs. $20 \%$ ), or both ( $42 \%$ vs. $7 \%$ ) (Figure $3, c-b)$. The intensity of immunostaining for these markers was also much greater in cells from wild-type mice. These findings suggest that lack of IL-12 results in a decreased number and quality of macrophages in the lung, and it is possible that this could be attributed in part to the lack of IFN- $\gamma$ release from these cells.

Marked release of IFN- $\gamma$, but not TNF- $\alpha$, by lung macrophages requires both $I L-12$ and mycobacteria. We have thus far demonstrated the release of type 1 cytokines IL-12, IFN- $\gamma$, and TNF- $\alpha$ from macrophages during pulmonary mycobacterial infection and the requirement of IL-12 for IFN- $\gamma$, but not TNF- $\alpha$, release. Because the macrophages 

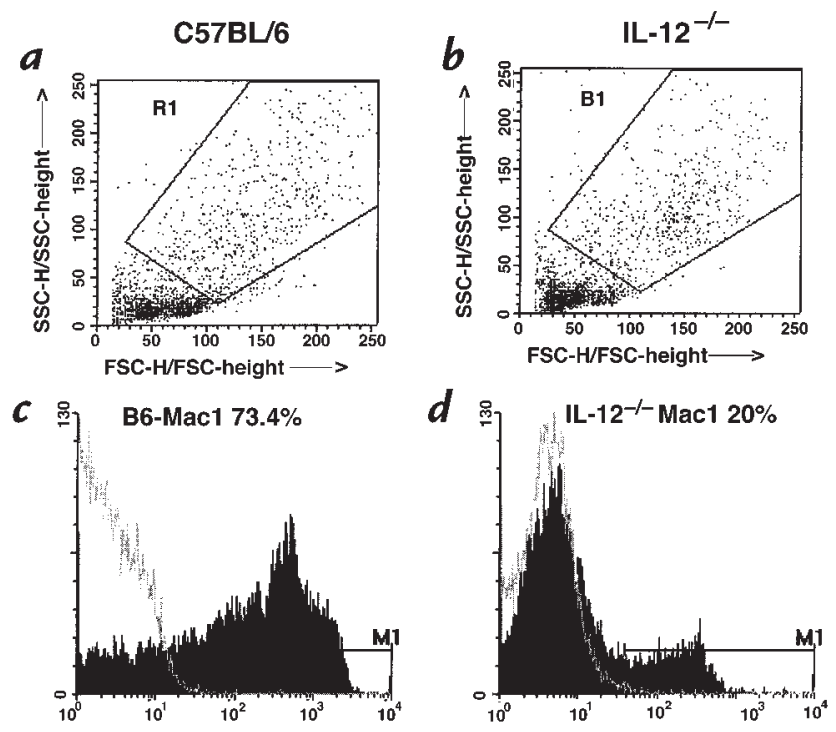

e
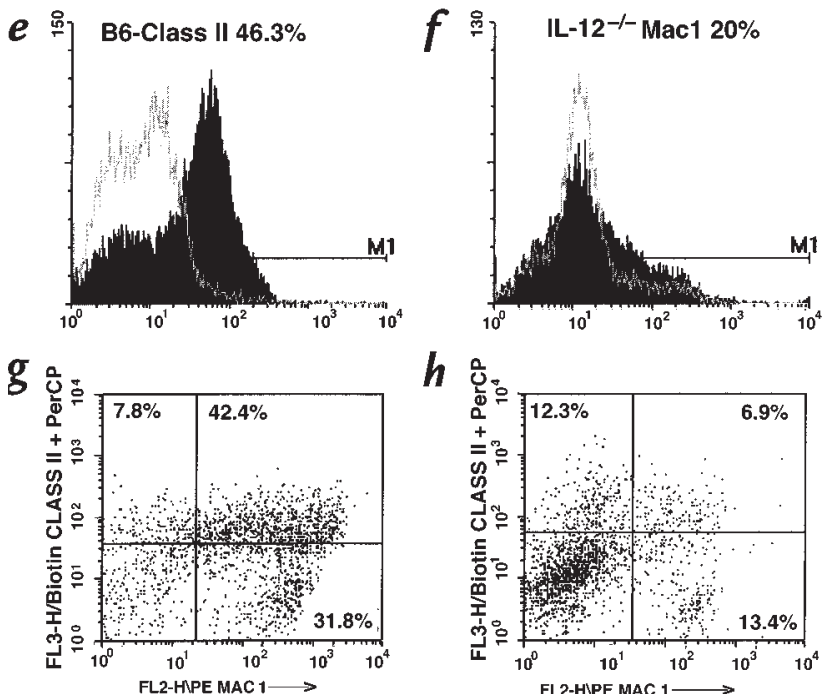

$h$

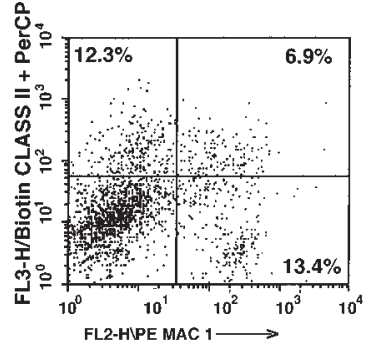

Figure 3

Analysis of macrophage activation phenotypes in C57BL/6 (a, $\boldsymbol{c}, \boldsymbol{e}$, and $\boldsymbol{g})$ vs. IL-12-/- mice $(\boldsymbol{b}, \boldsymbol{d}, \boldsymbol{f}$, and $\boldsymbol{h})$. Total lung mononuclear cells were isolated from two $\mathrm{C} 57 \mathrm{BL} / 6$ and four $\mathrm{IL}-12^{-/-}$mice 27 days after infection, immunostained, and analyzed for Mac 1 and MHC class II expression by FACS. Gating was set up on macrophage-rich cell populations ( $a$ and $b$ ), and analysis was carried out to identify cells positive for Mac 1 ( $c$ and $d$ ), MHC class II ( $e$ and $f$ ), or both ( $g$ and $h$ ).

isolated from infected wild-type mice were preactivated as a result of concurrent exposure to high concentrations of not only IL-12 but other type 1 cytokines, as well as to mycobacteria in the lung, it still remained to be determined whether IL-12 had a direct stimulatory effect on macrophage IFN- $\gamma$ release and whether this IFN- $\gamma$ response required both IL-12 and mycobacteria. To this end, we isolated lung macrophages from naive noninfected IL-12 $1 /-$ mice and examined IFN- $\gamma$ and TNF- $\alpha$ responses by these cells stimulated with either mycobacteria or IL12 alone, or both. As shown in Figure 4a, there was no IFN- $\gamma$ release with or without mycobacteria or LPS alone. A low level of IFN- $\gamma$ release, ranging from about 18 to 35 $\mathrm{pg} / \mathrm{ml}$, was observed when these cells were cultured with various doses of IL-12 alone (Figure $4 b$ ). However, a synergistic effect was seen when macrophages were stimulated with both IL-12 and LPS. The most striking synergistic effect was observed when cells were stimulated with both IL-12 and mycobacteria (Figure $4 b$ ). Under such conditions, IFN- $\gamma$ release appeared to be IL-12 dose-dependent, with the highest level being 1,200 pg/ml (Figure 4b). Because the macrophage population used in these experiments was more than $98 \%$ pure, it is unlikely that a small number of cells other than macrophages may have contributed significantly to the high level of IFN- $\gamma$ production under these conditions. To examine whether in addition to live mycobacteria or LPS, the second signal required for macrophage IFN- $\gamma$ release could be dead mycobacteria, mycobacterial antigens, or a nonmicrobial stimulus, we cultured lung macrophages from naive IL-12/- mice in the presence of IL-12 and heat-killed mycobacteria (DBCG), mycobacterial antigen (PPD), or a nonmicrobial antigen (OVA), and examined IFN- $\gamma$ response. Of note, while DBCG or PPD in the presence of IL-12 stimulated marked IFN- $\gamma$ release (although at lower levels compared with live mycobacterial stimulation), OVA with or without IL-12 failed to induce IFN- $\gamma$ release from lung macrophages (Figure 4c), in contrast to mycobacteria, PPD, or LPS (Figure $4 b$ ). Under the same culture conditions, however, OVA in the presence of IL-12 released approximately $150 \mathrm{pg} / \mathrm{ml}$ of TNF- $\alpha$. These results clearly demonstrate the critical requirement of both IL-12 and microbial agents, particularly intracellular pathogens, for optimal IFN- $\gamma$ response in macro-phages. To examine whether TNF- $\alpha$ release was IL-12-independent, we also measured TNF- $\alpha$ levels in supernatants from IL-12-/macrophages stimulated with mycobacteria or LPS alone. In sharp contrast to the lack of IFN- $\gamma$ release under these conditions (Figure $4 a$ ), TNF- $\alpha$ was markedly induced by stimulation with mycobacteria or LPS alone (Figure 5). In this respect, IL-12 alone had little effect on TNF- $\alpha$ release (data not shown). These results verified the findings obtained by using macrophages from infected IL-12-/lung that TNF- $\alpha$ response in macrophages during mycobacterial infection was IL-12-independent.

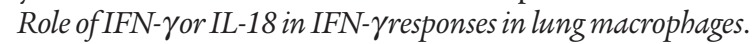
Because IFN- $\gamma$ has been shown to be capable of autoinduction in macrophages under certain conditions (16), we investigated whether IFN- $\gamma$ could replace IL- 12 in inducing IFN- $\gamma$ release by macrophages stimulated by mycobacteria, by examining the effect on IFN- $\gamma$ release of exogenously added IFN- $\gamma$ plus mycobacteria or LPS. Using a subtractive approach, we were able to estimate the amount of endogenously released IFN- $\gamma$ (see details in Figure 6 legend). While macrophages released significant

\section{Table 1}

The effect of anti-mouse IL-18 antibody on IFN- $\gamma$ release by macrophages

\begin{tabular}{lcccc}
\hline Anti-IL-18 $(\mu \mathrm{g} / \mathrm{ml})$ & 1,600 & 160 & 16 & 0 \\
IFN- $\gamma(\mathrm{pg} / \mathrm{ml})$ & $413.7 \pm 15.4$ & $453.3 \pm 43.3$ & $472.2 \pm 20.7$ & $475.5 \pm 22.8$
\end{tabular}

Lung macrophages were isolated from naive $\mathrm{IL}-12^{-/-}$mice and cultured in the presence of $200 \mathrm{pg} / \mathrm{ml}$ of IL-12 and $50 \mathrm{CFU} /$ cell of mycobacteria with or without various doses of murine IL-18 neutralizing antibodies. The supernatants collected at 72 $\mathrm{h}$ were measured for IFN- $\gamma$ by ELISA. The results are expressed as mean \pm SEM from triplicate determinations. IFN- $\gamma$, interferon- $\gamma ; I L$, interleukin. 
amounts of TNF- $\alpha$ in response to 20 and $200 \mathrm{pg} / \mathrm{ml}$ of IFN- $\gamma$ alone, they released little IFN- $\gamma$ (data not shown). When cultured with mycobacteria or LPS plus IFN- $\gamma$, particularly at $200 \mathrm{pg} / \mathrm{ml}$ concentration, macrophages released small amounts of IFN- $\gamma$ (Figure 6). However, these levels of induction were much lower than those from cells stimulated with mycobacteria or LPS plus the same concentrations of IL-12 (Figure $4 b$ ), suggesting that compared with IFN- $\gamma$, IL-12 is a much more important factor in IFN- $\gamma$ responses in macrophages. Inasmuch as IL-18 can be released by macrophages and synergize with IL-12 to stimulate IFN- $\gamma$ release from Th1 cells (4), we examined whether IL-18 may have potentiated IL-12-stimulated IFN- $\gamma$ response, by coculturing IL-12-/- macrophages with IL-12, mycobacteria, and a neutralizing antibody to murine IL-18. Even with the highest concentration of anti-IL-18 used (neutralizing 1,600 pg of IL-18), we observed only a $13 \%$ reduction in the level of IFN- $\gamma$ (Table 1 ), suggesting a minimal role, if any, for endogenously released IL-18 in the induction of IFN- $\gamma$ in macrophages upon stimulation by IL-12 and mycobacteria.

\section{Discussion}

In this study, we demonstrated that lung macrophages from immunocompetent wild-type mice were capable of producing type 1 cytokines IL-12, IFN- $\gamma$, and TNF- $\alpha$, and were phenotypically activated during pulmonary mycobacterial infection. In contrast, while macrophages from IL$12^{-/-}$mice had an unimpaired ability to produce TNF- $\alpha$, they failed to release IFN- $\gamma$ and lacked signs of activation. By using freshly isolated lung macrophages from IL-12-/mice, we further demonstrated that these cells released TNF- $\alpha$, but not IFN- $\gamma$, in response to mycobacterial or LPS stimulation. IL-12 alone induced a minimum amount of IFN- $\gamma$. However, when stimulated with both mycobacteria and IL-12, these macrophages released remarkable amounts of IFN- $\gamma$. In comparison to IL-12, exogenously added IFN- $\gamma$ had a much weaker stimulatory effect. We also found that IL-18 was not required in a significant way for IFN- $\gamma$ responses provoked by IL-12 and mycobacteria. Our data suggest that macrophages are a significant cellular source of type 1 cytokines in host responses against intracellular infection and that, contrary to TNF- $\alpha$ response by macrophages, IFN- $\gamma$ release is under tight control by both IL-12 and intracellular pathogens.

IFN- $\gamma$ plays a critical role in host defense against intracellular infections, including mycobacterial infection (1-3, $10,12)$. It has been widely believed that IL-12 released from activated macrophages stimulates Th1 cells, and to a certain degree NK cells, to release IFN- $\gamma$, which carries out its mission in cell-mediated immunity by potently activating macrophages as well as T cells $(1-4,22)$. Indeed, previous studies by ourselves and others have demonstrated an important role for IL- 12 and CD $4^{+}$T cell-derived IFN- $\gamma$ in host resistance to mycobacterial infection (7-13). The findings from our current study have furthered these studies and provided the first in vivo experimental evidence that macrophages are also a significant source of IFN- $\gamma$, in addition to IL-12 and TNF- $\alpha$, during pulmonary mycobacterial infection. Because antimicrobial granuloma is primarily composed of macrophages, macrophagederived IFN- $\gamma$, compared with T cell-derived IFN- $\gamma$, is like-
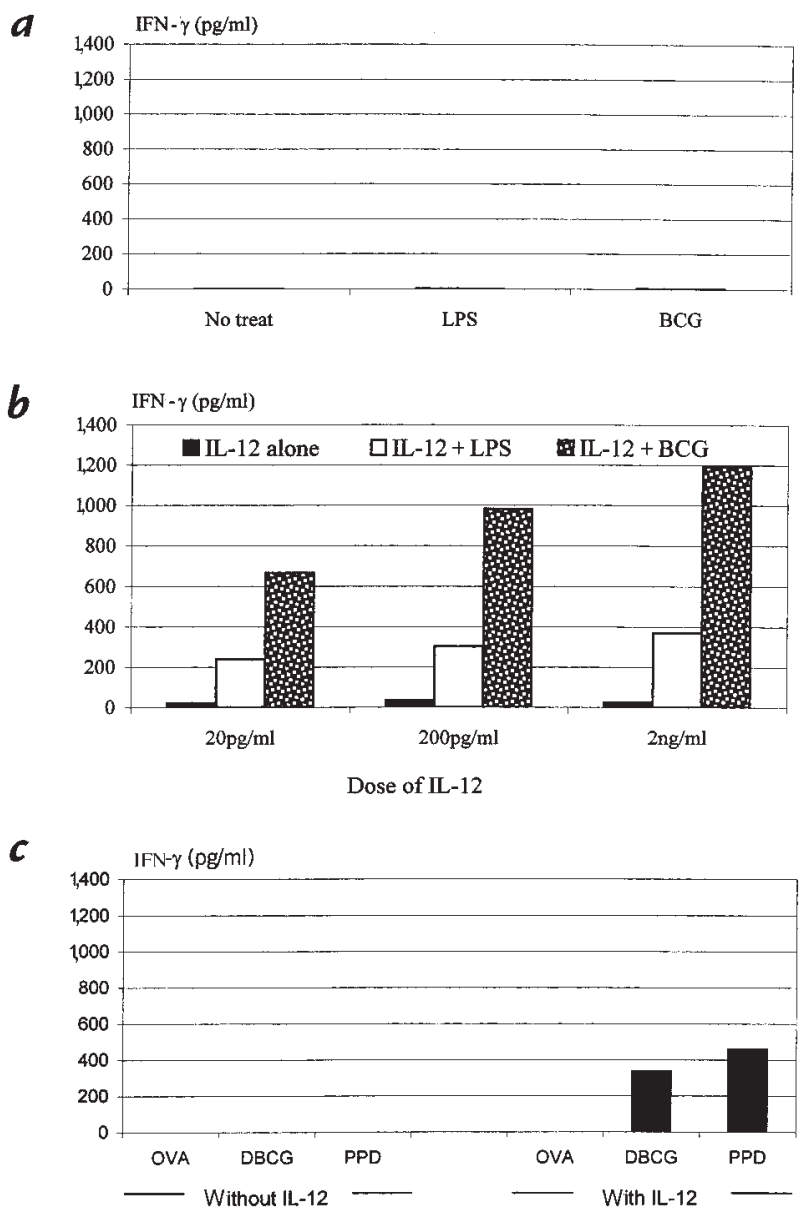

\section{Figure 4}

IFN- $\gamma$ production by freshly isolated lung macrophages from naive $\mathrm{IL}-12^{-1-}$ mice. Pulmonary macrophages were isolated and cultured under different conditions. The supernatants collected at $72 \mathrm{~h}$ were measured for IFN- $\gamma$ by ELISA. ( $a)$ Cells cultured with or without LPS $(1.6 \mu \mathrm{g} / \mathrm{ml})$ or live BCG (50 CFU/cell). (b) Cells cultured with $20 \mathrm{pg} / \mathrm{ml}, 200 \mathrm{pg} / \mathrm{ml}$, or 2 $\mathrm{ng} / \mathrm{ml}$ of IL-12 alone or together with $1.6 \mu \mathrm{g} / \mathrm{ml}$ of LPS or $50 \mathrm{CFU} / \mathrm{cell}$ of live BCG. (c) Cells stimulated with $400 \mu \mathrm{g} / \mathrm{ml}$ of OVA, DBCG (50 CFU/cell), or $8 \mu \mathrm{g} / \mathrm{ml}$ of PPD alone or together with $200 \mathrm{pg} / \mathrm{ml}$ of IL- 12 . The results are expressed as the means of duplicate samples and are representative of three to four independent experiments. OVA, ovalbumin; $D B C G$, heat-killed BCG.

ly even more effective in activating macrophages via an autocrine mechanism. Thus, the cell-mediated immune response is driven by IFN- $\gamma$ released from both Th 1 cells and macrophages. We found that macrophages released IFN- $\gamma$ only under specific stimulatory conditions and that an optimal IFN- $\gamma$ response requires not only IL-12 but also a microbial agonist, particularly an infectious intracellular pathogen. These findings have thus provided mechanistic insights into why macrophages normally do not release significant amounts of IFN- $\gamma$, in contrast to typical monokines $(6,14-16)$. In this regard, the lack of IL-12 release may hold the answer to why LPS, in contrast to mycobacterial bacilli, fails to induce IFN- $\gamma$ release from human alveolar macrophages in vitro (14).

Recently, recombinant IL-12 alone was shown to be ineffective in inducing IFN- $\gamma$ in freshly isolated peri- 
TNF- $\alpha(p g / m l)$

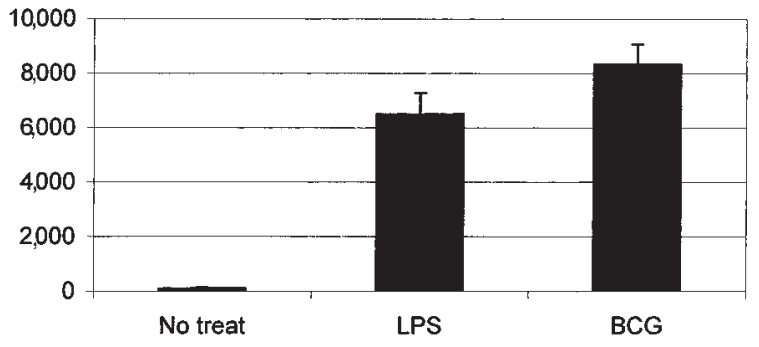

Figure 5

TNF- $\alpha$ production by freshly isolated lung macrophages from naive IL$12^{-/-}$mice. Lung macrophages and culture supernatants were prepared as in Figure 4. Supernatants were measured for TNF- $\alpha$ by ELISA. The results were expressed as means \pm SEM of duplicate samples from two separate experiments $(n=4)$.

toneal cells unless these cells were primed in culture for an extended period of time in the presence of repeated dosing of IL-12 (17). Yet, in another report, recombinant IL-12 alone was shown incapable of stimulating IFN- $\gamma$ release from bone marrow-derived macrophages unless cells were stimulated concurrently with high doses of both IL-12 and IL-18 (18). Of note, these cells were likely activated before IL-12/IL-18 stimulation by growth factors that were used to drive bone marrow cell differentiation to macrophages. This combined use of IL-12 and IL-18 failed to induce any IFN- $\gamma$ from commonly used murine macrophage cell lines (18). In comparison, not only have we provided unequivocal evidence to demonstrate the ability of in vivo activated macrophages to release large amounts of IFN- $\gamma$, we also have undertaken a series of in vitro studies by stimulating freshly isolated primary macrophage cultures. We have clearly shown that mycobacteria alone in the absence of IL-12 cannot stimulate IFN- $\gamma$ release, whereas IL-12 alone without mycobacteria can release only minimal amounts of IFN- $\gamma$, even when a physiologically relevant high dose of IL-12 (2 ng/ml) was used (we have previously documented a peak level of IL-12 in the lung of about $1 \mathrm{ng} / \mathrm{ml}$ during mycobacterial infection; ref. 7). A robust IFN- $\gamma$ response was observed only when these macrophages were costimulated by both mycobacteria and IL- 12 .

TNF- $\alpha$ is a well-known proinflammatory cytokine that is released by leukocytes, particularly macrophages, in response to numerous stimuli and is thus deemed an "alarm" or "stress" cytokine $(6,23)$. We have provided the first evidence that TNF- $\alpha$ release by macrophages is IL12 -independent, in contrast to IFN- $\gamma$. Furthermore, we have demonstrated that macrophage release of TNF- $\alpha$ is also IFN- $\boldsymbol{\gamma}$-independent, by showing that macrophages released large quantities of TNF- $\alpha$ in the absence of both IL-12 and IFN- $\gamma$. This IL-12-independent TNF- $\alpha$ response may explain why TNF- $\alpha$ gets released so readily under a variety of stimulatory conditions. In comparison, the host has apparently evolved a mechanism, mediated through IL-12, to control macrophage IFN- $\gamma$ response (Figure 7). Two forms of IL-12, p40 and p70, are secreted by macrophages, and only p 70 is biologically active $(3,4)$. Recent evidence suggests that unlike IL-12 p40, the active release of IL-12 p70 from macrophages may require a spe- cific set of signals (24-26), and it is likely that only intracellular pathogens can actively stimulate the release of IL12 p70. This contention may explain why mycobacteria can release IFN- $\gamma$ from macrophages but LPS and other stimuli cannot (14-16). Thus, marked IFN- $\gamma$ release results only from an encounter with intracellular pathogens by macrophages in vivo, a notion that appears to make sense immunologically in that IFN- $\gamma$ would be in the greatest demand when the host requires a full-blown macrophage activation to combat intracellular infections. In addition to its effect on macrophage activation, IFN- $\gamma$ may also enhance Th1 differentiation by augmenting IL$12 \mathrm{R} \beta 2$ expression on T cells (27). This notion is further supported by our findings that only mycobacteria or virus (data not shown), but not OVA antigen, in the presence of IL-12 can effectively stimulate IFN- $\gamma$ release from macrophages. In addition to its effect on IFN- $\gamma$ release by macrophages, IL-12 is apparently an important switch for Th1 differentiation and IFN- $\gamma$ response by Th1 and NK cells $(3,4)$. Thus, IFN- $\gamma$ released from T cells and macrophages, perhaps together with TNF- $\alpha$, may most effectively activate macrophages, enhancing their bactericidal activities (Figure 7 ).

Since recombinant IFN- $\gamma$ has been shown to stimulate endogenous production of IFN- $\gamma$ in peritoneal cells (16), we compared the relative potency of IL-12 and IFN- $\gamma$ in inducing endogenous IFN- $\gamma$ release in the presence of mycobacteria or LPS. We found that IL12 -induced IFN- $\gamma$ response was much more pronounced than that by IFN- $\gamma$, suggesting a minor role for IFN- $\gamma$ in autoinduction of IFN- $\gamma$ release from macrophages provoked by IL-12 and mycobacteria. However, we did find a stronger TNF- $\alpha$ response by macrophages stimulated by IFN- $\gamma$ with or without mycobacteria than that by IL-12 with or without mycobacteria. These data suggest that IL-12 is specialized in stimulating macrophages to release IFN- $\gamma$,

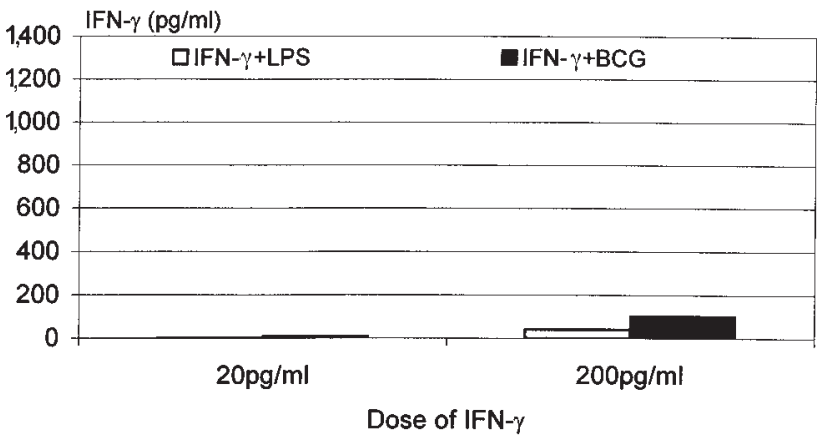

\section{Figure 6}

The effect of exogenously added IFN- $\gamma$ on IFN- $\gamma$ autoinduction by freshly isolated lung macrophages from naive $\mathrm{IL}-12^{-/-}$mice. Lung macrophages were cultured with $20 \mathrm{pg} / \mathrm{ml}$ or $200 \mathrm{pg} / \mathrm{ml}$ of IFN- $\gamma$ alone or in combination with $1.6 \mu \mathrm{g} / \mathrm{ml}$ of LPS or $50 \mathrm{CFU} /$ cell of live BCG for $72 \mathrm{~h}$. The supernatants were measured for IFN- $\gamma$ by ELISA. Little IFN- $\gamma$ was induced with the dose of IFN- $\gamma$ alone (data not shown). The release of endogenous IFN- $\gamma$ was estimated by subtracting the amount of IFN- $\gamma$ in cultures containing exogenously added IFN- $\gamma$ alone from that measured in cultures containing both added IFN- $\gamma$ and mycobacteria or LPS. The results are expressed as mean values of duplicate samples and are representative of two independent experiments. 


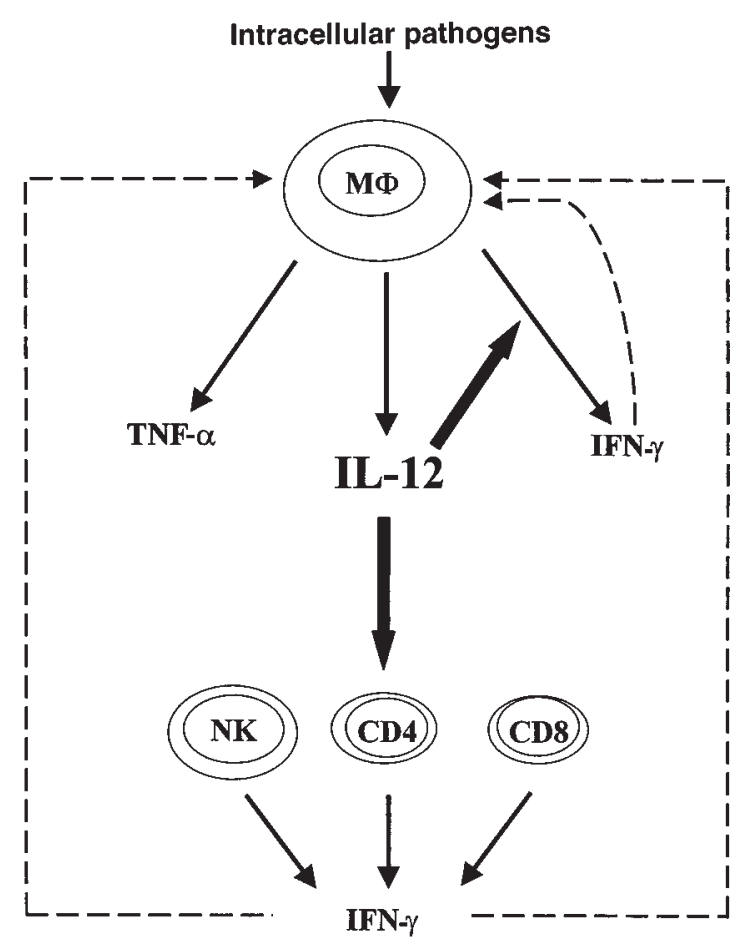

Figure 7

Schematic model for the role of IL-12 in type 1 cytokine cascades in both $T$ cells and macrophages during intracellular infection. Upon interaction with intracellular pathogens such as mycobacteria, macrophages release IL-12 and TNF- $\alpha$. The release of TNF- $\alpha$ is IL-12-independent. The essential role of IL-12 in host responses rests, in part, on its potent effect on IFN- $\gamma$ production from different cell types. On one hand, it stimulates Th1 differentiation and IFN- $\gamma$ production from $\mathrm{CD}^{+} \mathrm{Th} 1$ cells. This IFN$\gamma$ activates macrophages via a paracrine mechanism. On the other hand, IL-12, together with intracellular pathogens, stimulates IFN- $\gamma$ release from macrophages. This IFN- $\gamma$ may activate macrophages via a potent autocrine mechanism. Two macrophage activation pathways through IFN- $\gamma$ are indicated with broken lines.

whereas IFN- $\gamma$ is able to activate many functional activities of macrophages.

IL-18 (IFN- $\gamma$-inducing factor), a recently identified cytokine, can be released from macrophages and structural tissue cell types and has been shown to synergize with IL-12 to induce IFN- $\gamma$ from Th 1 and NK cells (4). We investigated whether endogenous IL-18 may play a role in IFN- $\gamma$ response in macrophages stimulated by IL-12 and mycobacteria. We found that IL-18 played a negligible role, if any, in IFN- $\gamma$ release under these conditions. Moreover, our finding from both in vivo and in vitro studies that in the absence of IL-12, neither mycobacteria nor LPS induced significant amounts of IFN- $\gamma$, suggests that IL-18 cannot fill the function of IL-12 in this regard.

In summary, we have provided experimental evidence that macrophages are a significant source of type 1 cytokines during mycobacterial infection and that TNF$\alpha$ and IFN- $\gamma$ are differentially regulated, with TNF- $\alpha$ requiring only microbial agents and IFN- $\gamma$ requiring both intracellular pathogens and IL-12. These findings support a central role by IL- 12 in governing IFN- $\gamma$ responses not only in $\mathrm{T}$ cells but also in tissue macrophages.

\section{Acknowledgments}

The authors wish to thank Anna Zganiacz for her invaluable technical assistance, Jack Gauldie for his support of this work, Jeanne Magram for allowing us access to IL-12-/- mice, and Sara DeSilvio for her secretarial assistance. This study was supported by the Ontario Thoracic Society. Zhou Xing is a scholar of the Medical Research Council, Canada.

1. Cooper, A.M., and Flynn, J.L. 1995. The protective immune response to Mycobacterium tuberculosis. Curr. Opin. Immunol. 7:512-516.

2. Orme, I.M., Andersen, P., and Boom, W.H. 1993. T cell response to Mycobacterium tuberculosis. J. Infect. Dis. 167:1481-1497.

3. Trinchieri, G. 1995. Interleukin-12: a proinflammatory cytokine with immunoregulatory functions that bridge innate resistance and antigenspecific adaptive immunity. Annu. Rev. Immunol. 13:251-276.

4. Okamura, H., Kashiwamura, S., Tsutsui, H., Yoshimoto, T., and Nakanishi, K. 1998. Regulation of interferon-gamma production by IL-12 and IL-18. Curr. Opin. Immunol. 10:259-264.

5. Mosmann, T.R., and Sad, S. 1996. The expanding universe of T-cell subsets: Th1, Th2 and more. Immunol. Today. 17:138-146.

6. Xing, Z., Jordana, M., Gauldie, J., and Wang, J. 1999. Cytokines and pulmonary inflammatory and immune diseases. Histol. Histopathol. 14:185-201.

7. Wakeham, J., et al. 1998. Lack of both types 1 and 2 cytokines, tissue inflammatory responses, and immune protection during pulmonary infection by Mycobacterium bovis bacille Calmette-Guérin in IL-12-deficient mice. J. Immunol. 160:6101-6111.

8. Xing, Z., Wang, J., Croitoru, K., and Wakeham, J. 1998. Protection by CD4 or CD8 T cells against pulmonary Mycobacterium bovis bacillus Calmette-Guérin infection. Infect. Immun. 66:5537-5542.

9. Cooper, A.M., Magram, J., Ferrante, J., and Orme, I.M. 1997. Interleukin 12 (IL-12) is crucial to the development of protective immunity in mice intravenously infected with Mycobacterium tuberculosis. J. Exp. Med. 186:39-45.

10. Flynn, J.L., et al. 1993. An essential role for interferon gamma in resistance to Mycobacterium tuberculosis infection. J. Exp. Med. 178:2249-2254.

11. Flynn, J.L., et al. 1995. Tumor necrosis factor alpha is required in the protective immune response against Mycobacterium tuberculosis in mice. Immunity. 2:561-572.

12. Jouanguy, E., et al. 1997. Interferon-gamma receptor deficiency in an infant with fatal BCG infection. N. Engl. J. Med. 335:1956-1961.

13. Altare, F., et al. 1998. Impairment of mycobacterial immunity in human interleukin-12 receptor deficiency. Science. 280:1432-1435.

14. Fenton, M.J., et al. 1997. Induction of gamma interferon production in human alveolar macrophages by Mycobacterium tuberculosis. Infect. Immun. 65:5149-5156.

15. Fultz, M.J., Barber, S.A., Dieffenbach, C.W., and Vogel, S.N. 1993. Induction of IFN gamma in macrophages by LPS. Int. Immunol. 5:1383-1392.

16. Marzio, P.D., et al. 1994. Interferon gamma upregulates its own gene expression in mouse peritoneal macrophages. J. Exp. Med. 179:1731-1736.

17. Puddu, P., et al. 1997. IL-12 induces IFN-gamma expression and secretion in mouse peritoneal macrophages. J. Immunol. 159:3490-3497.

18. Munder, M., Mallo, M., Eichmann, K., and Modolell, M. 1998. Murine macrophages secrete interferon gamma upon combined stimulation with interleukin (IL)-12 and IL-18: a novel pathway of autocrine macrophage activation. J. Exp. Med. 187:2103-2108.

19. Magram, J., et al. 1996. IL-12-deficient mice are defective in IFN gamma production and type 1 cytokine responses. Immunity. 4:471-481.

20. Bramson, J., et al. 1996. Construction of a double recombinant adenovirus vector expressing a heterodimeric cytokine: in vitro and in vivo production of biologically active interleukin-12. Hum. Gene Ther. 7:333-342.

21. Xing, Z., et al. 1994. Adenovirus-mediated cytokine gene transfer at tissue sites. Over-expression of IL-6 induces lymphocytic hyperplasia in the lung. J. Immunol. 153:4059-4069.

22. Kaplan, G., and Freedman, V.H. 1997. The role of cytokines in the immune response to tuberculosis. Res. Immunol. 147:565-572.

23. Willeaume, V., Kruys, V., Mijatovic, T., and Huez, G. 1995. Tumor necrosis factor-alpha production induced by viruses and by lipopolysaccharides in macrophages: similarities and differences. J. Inflamm. 46:1-12.

24. Bonecini-Almeida, M.G., et al. 1998. Induction of in vitro human macrophage anti-Mycobacterium tuberculosis activity: requirement for IFN-gamma and primed lymphocytes. J. Immunol. 160:4490-4499.

25. von Stebut, E., Belkaid, Y., Jokob, T., Sacks, D.L., and Udey, M.C. 1998. Uptake of Leishmania major amastigotes results in activation and interleukin-12 release from murine skin-derived dendritic cells: implication for the initiation of anti-Leishmania immunity. J. Exp. Med. 188:1547-1552.

26. Flesch, I.E.A., et al. 1995 . Early interleukin- 12 production by macrophages in response to mycobacterial infection depends on interferon-gamma and tumor necrosis factor-alpha. J. Exp. Med. 181:1615-1622.

27. Wenner, C.A., Guler, M.L., Macatonia, S.E., Ogarra, A., and Murphy, K.M. 1996. Roles of IFN- gamma and IFN-alpha in IL-12-induced T helper cell-1 development. J. Immunol. 156:1442-1447. 